\title{
Influence of waste calcareous rock powder on concrete transmission performance
}

\author{
Jianping Cheng, * \\ ${ }^{1}$ The 4th Engineering Co., Ltd., of China Railway 12th Bureau Group, Xi'an 710021, Shangxi, China
}

\begin{abstract}
Reuse of stone powder formed in the production of manufactured sand is of great significance to environmental protection and resource utilization. In this paper, the waste calcareous rock powder formed in the manufactured sand production line was added into the concrete by $6 \%, 9 \%, 12 \%$ and $15 \%$, and the total weight of manufactured sand and rock powder was controlled to be constant to prepare C30 and C40 environment-friendly manufactured sand concrete. The influence of rock powder on the compressive strength and transmission performance of concrete was analyzed. It was found that with the increase of stone powder content, the compressive strength of fresh paste and C30 concrete first increased and then decreased, while the concrete transmission performance and the compressive strength of $\mathrm{C} 40$ concrete continued to decline. It was suggested that the content of rock powder should not exceed $9 \%$.
\end{abstract}

\section{Introduction}

In recent years, large-scale engineering construction makes the high-quality natural sand resources increasingly scarce. Natural sand mining has become a scarce resource after strict management and policy control. With the continuous development of manufactured sand production technology, the quality, supply and use technology of manufactured sand are steadily improved, which makes manufactured sand gradually become an irreplaceable key material for concrete production. In the process of manufactured sand production, a large amount of stone powder is inevitably produced during the crushing process of rock stone. According to the investigation, the preparation of one ton of manufactured sand product was accompanied by the formation of $150 \mathrm{~kg}$ $\sim 200 \mathrm{~kg}$ stone powder [1-3]. If stacking or landfill treatment was adopted, it will not only occupy the site, cause dust flying and water pollution, but also greatly reduce the utilization rate of energy and manufactured sand resources. On the other hand, the application specification of manufactured sand allowed the use of manufactured sand with appropriate stone powder content to prepare concrete. However, the influence of stone powder content on the comprehensive performance of concrete need in-depth experimental analysis to form a comprehensive and reliable mix design method of manufactured sand concrete. In order to protect natural resources and environment and reduce the production cost of manufactured sand, it was of great significance to recycle manufactured sand powder to prepare green environmental protection concrete.

At present, Kishan et al. [4] prepared green concrete with granite waste stone powder and glass powder and observed that the water permeability and water absorption of hardened paste were significantly improved. Iman et al. [5] evaluated the influence of marble and granite waste dust on the corrosion resistance of steel bars in concrete by statistical analysis method and found that $10 \%$ granite powder and $10 \%$ marble powder can replace cement to improve the open circuit potential and electrochemical impedance of ordinary concrete. Ding [6] studied the influence of different water binder ratio on the content of limestone manufactured sand and stone powder and found that with the decrease of water binder ratio, the appropriate value of manufactured sand and stone powder content decreased. Yan et al [7] considered that the comprehensive performance of HPC is best when the manufactured sand contains $7.0 \mathrm{wt} . \%$ stone powder. Xie et al. [8] considered that if the content of manufactured sand and stone powder is more than $6 \%$, the mechanical properties of concrete prepared will be lower than that of natural sand concrete and found that when the content of manufactured sand and stone powder increases, the mechanical properties of concrete first strengthen and then weaken. Sun [9] thinks that the best stone powder content of manufactured sand in $\mathrm{C} 30$ concrete is $10 \%$ $15 \%$, and the best stone powder content of manufactured sand in C50 concrete is $7 \% \sim 10 \%$.

In order to improve the utilization rate of rock powder by-products formed in the production of manufactured sand, reduce the occupied area of the site, master the influence law of rock powder on the performance of concrete, and form the green design concept of sustainable development of manufactured sand concrete, this paper used the waste calcareous rock powder formed in the production of manufactured sand to be mixed into concrete. The influence of water binder ratio on mechanical strength and transmission performance of ordinary concrete was studied.

\footnotetext{
* Corresponding author: 1290451762@qq.com
} 


\section{Material and testing method}

\subsection{Raw material}

The apparent density of manufactured sand is $2690 \mathrm{~kg} / \mathrm{m}^{3}$, the loose bulk density is $1600 \mathrm{~kg} / \mathrm{m}^{3}$, the porosity of loose bulk is $41 \%$, the content of stone powder is $10.2 \%$, the fineness modulus is 2.94 , the water demand ratio is $103 \%$, the $\mathrm{MB}$ value is 0.75 , and the maximum crushing index of single stage is $16.5 \%$. The crushed stone used is composed of $5-10 \mathrm{~mm}, 10-20 \mathrm{~mm}$ and $31.5 \mathrm{~mm}$ graded crushed stone with mass ratio of $2: 5: 3$. The content of needle flake particles is $0.6 \%$, and the maximum crushing index of single stage is $8.7 \%$.

The waste calcareous rock powder was collected from the limestone manufactured sand production line and screened by $0.075 \mathrm{~mm}$ screen. The test results showed that the fluidity ratio was $106 \%$, the water demand ratio was $98.30 \%$, the $\mathrm{MB}$ value was 3.8 , the specific surface area was $900.21 \mathrm{~kg} / \mathrm{m}^{3}$, the density was $2655 \mathrm{~kg} / \mathrm{m}^{3}$, the water content was $0.41 \%$, and the $7 \mathrm{~d}$ activity index was $90 \%$.
Using P.O. 42.5 cement, standard consistency 27.1\%, specific surface area $326 \mathrm{~m}^{2} / \mathrm{kg}$, initial setting time $161 \mathrm{~min}$, final setting time $246 \mathrm{~min}, 3 \mathrm{~d}$ strength $32.2 \mathrm{MPa}, 28 \mathrm{~d}$ strength $57.5 \mathrm{MPa}$. Type F class II fly ash is used, with fineness of $13.2 \%$ ( $45 \mu \mathrm{m}$ sieve residue) and $28 \mathrm{~d}$ activity index of $74 \%$. Using polycarboxylate water reducer, the solid content is $30.2 \%$, and the water reducing rate is $28 \%$.

\subsection{Mix proportion}

The influence of waste calcareous rock powder on the performance of manufactured sand concrete was shown in Table 1. The water-to-binder ratio (W/B) of 0.44 and 0.38 were designed respectively to prepare $\mathrm{C} 30$ and $\mathrm{C} 40$ strength grade concrete and compare the influence of W/B. The total weight of manufactured sand and waste calcareous rock powder in $\mathrm{C} 30$ was $798 \mathrm{~kg} / \mathrm{m}^{3}$, and that in $\mathrm{C} 40$ was $814 \mathrm{~kg} / \mathrm{m}^{3}$. The amount of rock powder in brackets after the weight of rock powder was $6 \%, 9 \%, 12 \%$ and $15 \%$ respectively.

Table 1 Mix proportion of influence of content of waste calcareous rock powder on mechanical properties of concrete $\left(\mathrm{kg} / \mathrm{m}^{3}\right)$

\begin{tabular}{|c|c|c|c|c|c|c|c|}
\hline Sample ID & Cement & Fly ash & Manufactured sand & Waste calcareous rock powder & Coarse aggregate & Water & W/B \\
\hline C30-S-6 & 294 & 74 & 750 & $48(6 \%)$ & 1058 & 162 & \\
\hline C30-S-9 & 294 & 74 & 726 & $72(9 \%)$ & 1058 & 162 \\
\hline C30-S-12 & 294 & 74 & 702 & $96(12 \%)$ & 1058 & 162 \\
\hline C30-S-15 & 294 & 74 & 678 & $120(15 \%)$ & 1058 & 162 & \\
\hline C40-S-6 & 341 & 85 & 765 & $49(6 \%)$ & 994 & 162 \\
\hline C40-S-9 & 341 & 85 & 741 & $73(9 \%)$ & 994 & 162 \\
\hline C40-S-12 & 341 & 85 & 716 & $98(12 \%)$ & 994 & 162 \\
\hline C40-S-15 & 341 & 85 & 692 & $122(15 \%)$ & 994 & 162 & \\
\hline
\end{tabular}

\subsection{Testing method}

The compressive strength of hardened concrete was tested in accordance with the Standard for test method of mechanical properties on ordinary concrete (GB/T 50081-2019). The size of compressive strength test specimen was $100 \mathrm{~mm}$ cube, and the test age was $3 \mathrm{~d}, 7 \mathrm{~d}$, $28 \mathrm{~d}$ and $56 \mathrm{~d}$. The transmission performance of concrete had a profound impact on the durability of concrete [10]. In order to analyse the impact of waste calcareous rock powder on the transmission performance of concrete, this paper evaluated the transmission performance of concrete based on the rapid chloride diffusion coefficient $\left(\mathrm{D}_{\mathrm{RCM}}\right)$ and carbonation depth test, and the test operation followed the Standard for Test Methods of Long-Term Performance and Durability of Ordinary Concrete (GB/T50082-2009), The test age of $\mathrm{D}_{\mathrm{RCM}}$ was 28 days and 56 days, and the test age of carbonation depth was $3 \mathrm{~d}, 7 \mathrm{~d}$ and $28 \mathrm{~d}$.

\section{Result and discussion}

\subsection{Compressive strength}

The test results of the influence of concrete prepared with waste calcareous rock powder on its strength were shown in Table 2. The solid line symbol represents C30 concrete, and the dotted line symbol represented C40 concrete. With the increase of stone powder content, the strength of C30 concrete at different ages first increased and then decreased. The strength of C30-S-9 specimen was the highest at each age, and its $56 \mathrm{~d}$ strength was $65.5 \mathrm{MPa}$. Although the strength of C30-S-15 specimen was low, its $56 \mathrm{~d}$ strength can still reach $61.1 \mathrm{MPa}$. It can be seen that the increase of stone powder content from $9 \%$ to $15 \%$ had little effect on the strength of $\mathrm{C} 30$ concrete. The strength of $\mathrm{C} 40$ concrete decreased with the increase of stone powder content. At 56d, the strength of C40-S-9 group was $70.8 \mathrm{MPa}$, and that of $\mathrm{C} 40-\mathrm{S}-15$ group was $65.6 \mathrm{MPa}$. It can be seen that the weakening effect of stone powder content on the compressive strength of high strength concrete was more prominent. On the other hand, by comparing the strength data of concrete with different water binder ratio at the same age, it can be seen that the change of water binder ratio has little effect on the early strength of concrete at $9 \%$ and $12 \%$ dosage.

Therefore, for the concrete with different cementitious material dosage and strength requirements, there were differences in the optimal stone powder content of manufactured sand. As shown in Table 2, the stone powder content of $\mathrm{C} 30$ concrete was about $9 \%$, and that of $\mathrm{C} 40$ concrete was about $6 \%$, which was basically close to the existing research $[11,12]$. 
Table 2 Effect of content of waste calcareous rock powder on cube compressive strength of concrete

\begin{tabular}{|c|c|c|c|c|c|c|c|c|}
\hline $\begin{array}{c}\text { Conetent of waste } \\
\text { calcareous rock powder (\%) }\end{array}$ & C30-3d & C30-7d & C30-28d & C30-56d & C40-3d & C40-7d & C40-28d & C40-56d \\
\hline 6 & 35.7 & 41.4 & 56.2 & 61.0 & 41.8 & 53.3 & 65.1 & 70.8 \\
\hline 9 & 38.5 & 46.2 & 60.2 & 65.5 & 38.6 & 47.4 & 60.7 & 67.2 \\
\hline 12 & 38.1 & 45.9 & 57.0 & 62.3 & 39.1 & 49.0 & 61.5 & 68.1 \\
\hline 15 & 32.3 & 42.0 & 56.6 & 61.1 & 36.2 & 48.3 & 58.7 & 65.6 \\
\hline
\end{tabular}

Table 3 Prediction model parameters of carbonation reaction of waste calcareous rock powder concrete

\begin{tabular}{|c|c|c|c|c|c|c|c|c|}
\hline Age/d & C30-S-6 & C30-S-9 & C30-S-12 & C30-S-15 & C40-S-6 & C40-S-9 & C40-S-12 & C40-S-15 \\
\hline$a$ & 0.021 & 0.889 & 0.479 & 0.634 & 0.389 & -0.357 & 0.008 & 0.553 \\
\hline$b$ & 1.893 & 1.941 & 2.038 & 2.191 & 1.738 & 1.776 & 1.874 & 1.993 \\
\hline $\mathrm{R}^{2}$ & 0.991 & 0.987 & 0.99 & 0.984 & 0.91 & 0.985 & 0.992 & 0.983 \\
\hline
\end{tabular}

\subsection{Rapid chloride diffusion coefficient}

The amount of waste calcareous rock powder in each mix proportion was listed in detail in column 5 of Table 1 . The test results of $\mathrm{D}_{\mathrm{RCM}}$ of waste calcareous rock powder concrete cured to $28 \mathrm{~d}$ and $56 \mathrm{~d}$ were plotted in Fig. 1 with the weight of stone powder as the fan angle value. The larger the arc in the Fig. was, the higher the amount of stone powder was.

With the content of waste calcareous rock powder increased from $6 \%$ to $15 \%$, the $\mathrm{D}_{\mathrm{RCM}}$ of $\mathrm{C} 30$ and $\mathrm{C} 40$ concrete increased gradually. For example, the $\mathrm{D}_{\mathrm{RCM}}$ of C30-S-6 to C30-S-15 samples at $56 \mathrm{~d}$ were $5.6 \times 10^{-12} \mathrm{~m}^{2} / \mathrm{s}$ 、 $4.8 \times 10^{-12} \mathrm{~m}^{2} / \mathrm{s}$ 、 $5.9 \times 10^{-12} \mathrm{~m}^{2} / \mathrm{s}$ and $6.5 \times 10^{-12} \mathrm{~m}^{2} / \mathrm{s}$. Compared with $\mathrm{C} 30-\mathrm{S}-6$, the latter three groups increased by $-8.74 \%, 5.88 \%$ and $6.67 \%$ respectively. The hydration activity of waste rock powder used in this paper was very low, and the density of concrete paste can only be improved in a limited range by filling effect and nucleation effect after mixing with concrete. However, due to the low bonding degree between the particles, hydration products and hindering the extension and intersection of whiskers between hydration products, the three-dimensional random distribution network skeleton structure of paste was weakened. It can be seen from Table 2 and Fig. 1 that C30-S-9 with 9\% rock powder content had higher compressive strength and lower $\mathrm{D}_{\mathrm{RCM}}$ value, which indicated that adding $9 \%$ rock powder in the scope of this study was more beneficial to the performance of concrete.

Fig. 1 also showed that prolonging the curing period of concrete can effectively reduce the chloride ion diffusion resistance of waste calcareous rock powder concrete, that was, reduce the transmission performance of concrete. With the age increasing from $28 \mathrm{~d}$ to $56 \mathrm{~d}$, the $\mathrm{D}_{\mathrm{RCM}}$ of C30 and C40 concrete with different amount of stone powder decreased significantly. For example, the $28 \mathrm{~d} \mathrm{D}_{\mathrm{RCM}}$ of C40-S-15 group was $11 \times 10^{-12} \mathrm{~m}^{2} / \mathrm{s}, 6.1 \times 10^{-}$ ${ }^{12} \mathrm{~m}^{2} / \mathrm{s}$ at $56 \mathrm{~d}$. When the age was extended, cementitious particles will produce more calcareous silicate hydrates. Meanwhile, the fly ash contained in the slurry played a volcano ash effect, further producing C-S-H gel with high silica-calcareous ratio [13]. Increasing hydration products will fill in the slurry pores and then reduce the pore size and connectivity, making the paste structure denser, which was beneficial to improve the concrete's ability to resist chloride ion penetration.

It can be seen from Fig. 2 that the increase of concrete compressive strength was accompanied by the decrease of $\mathrm{D}_{\mathrm{RCM}}$ value, which means that there was a good correlation between the compressive strength of waste calcareous rock powder concrete and the rapid chloride ion diffusion coefficient. Concrete strength was the macro reflection of internal micro compactness and pore structure. High compressive strength often required the paste to have a dense structure, while the transmission performance of dense paste was low, so the chloride ion diffusion rate was slow, and its diffusion coefficient was small [8,14-17].

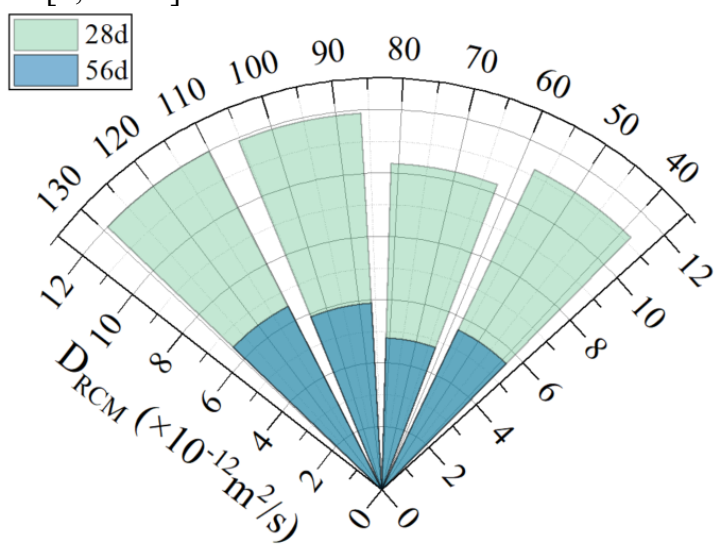

(a) $\mathrm{C} 30$ concrete

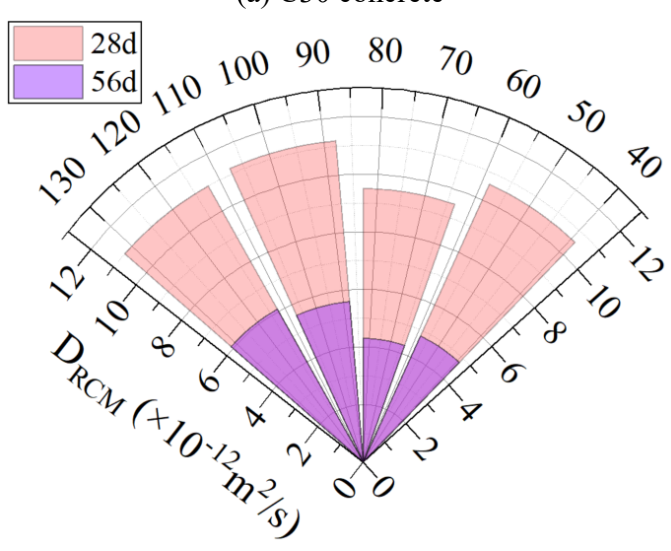

(b) $\mathrm{C} 40$ concrete

Fig. 1 Test results of rapid chloride ion diffusion coefficient of waste calcareous rock powder concrete 


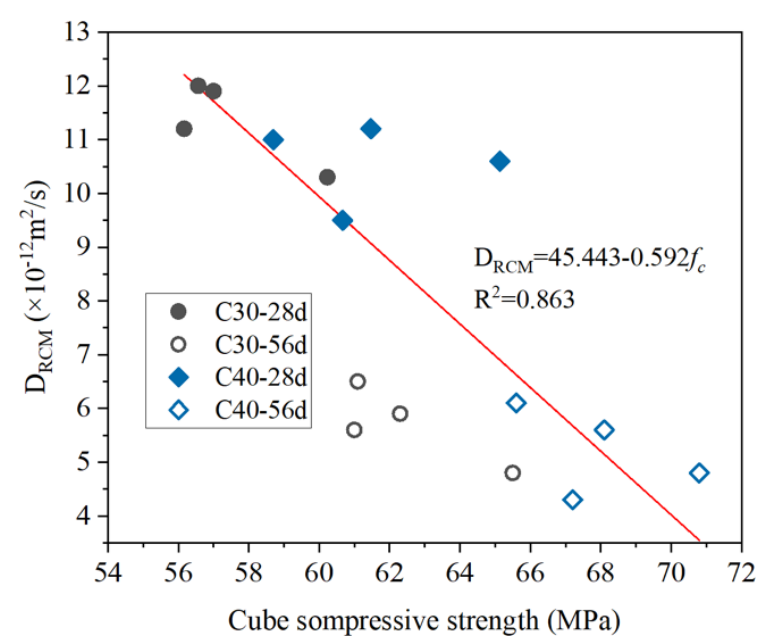

Fig. 2 Correlation between compressive strength of waste calcareous rock powder concrete and rapid chloride ion diffusion coefficient

\subsection{Carbonation depth}

In order to further analyze the influence of adding waste calcareous rock powder on the transmission performance of concrete, this paper used carbon dioxide gas as the invasion fluid medium for the test, and the relevant test results were shown in Fig. 3. With the extension of carbon dioxide invasion time, the carbonation depth of concrete with different strength grades increased gradually. On the other hand, the carbonation depth of concrete increased with the increase of stone powder content. When the age was 28 days, the carbonation depth of C30-S-6 to C30-S15 groups were $6.2 \mathrm{~mm}, 6.5 \mathrm{~mm}, 6.8 \mathrm{~mm}$ and $7.3 \mathrm{~mm}$ respectively, and the increase rates of the latter three groups were $4.84 \%, 9.68 \%$ and $17.74 \%$ respectively compared with $\mathrm{C} 30-\mathrm{S}-6$. Reducing the water binder ratio can counteract the negative effect of rock powder. For example, the carbonation depth of C40-S-15 group was $6.5 \mathrm{~mm}$ on the 28th day, which was consistent with C30S-9, and decreased by $10.96 \%$ compared with C30-S-15 group.

As a result of carbonation reaction, a series of reactions will take place in the carbonation zone of concrete surface, including the decrease of alkalinity of pore solution, the shrinkage of slurry and the formation of stress and strain gradient field, which will lead to the cracking risk of concrete surface. In order to form the anticarbonation protection design method of waste calcareous rock powder concrete and slow down the adverse effect of carbonation reaction, the logarithmic model of equation (1) was used to make regression analysis on the test results in Fig. 3

$$
D_{\mathrm{CO} 2}=b^{*} \ln (t+a)
$$

Where $t$ was the carbonation reaction time (d), $a$ and $b$ were the regression constants, and $D_{\mathrm{CO} 2}$ was the prediction of carbonation depth. The parameters of carbonation depth prediction model of different mix proportion concrete in Table 1 were shown in Table 3 , and the corresponding regression curve was shown in Fig. 3. It can be seen from Fig. 3 that the fitting curve of equation (1) was in good agreement with the variation law of the measured value of carbonation depth.
We used the quadratic function model to perform regression analysis on the correlation between the concrete carbonation depth and the cubic compressive strength, as shown in Fig. 4. It can be found that as the compressive strength of concrete decreased, the carbonation depth also decreased, that was, there was a good correlation between the two. Similar to the rapid chloride ion diffusion coefficient, the carbonation depth test reflected the difficulty of the transfer between the internal material of the hardened concrete specimen and the external environment from the side. The anticarbonization performance of concrete was closely related to factors such as the type and amount of cement, the type of admixture, the water-binder ratio, and the admixtures. These factors can also have a significant impact on the compressive strength of concrete. For ordinary concrete, when the compressive strength was higher, it indicates that the degree of hydration of the paste was relatively high, and the sample has formed a denser pore structure, which can effectively delay the carbonization rate of the concrete.

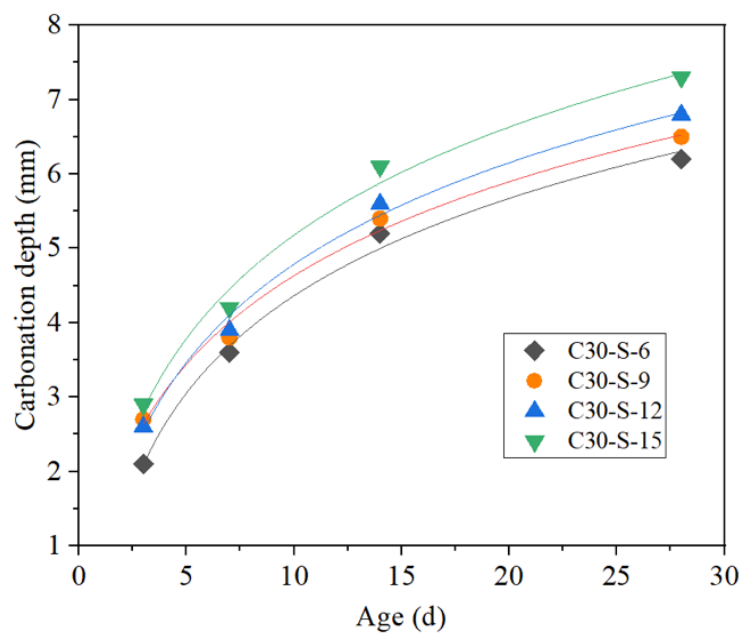

(a) $\mathrm{C} 30$ concrete

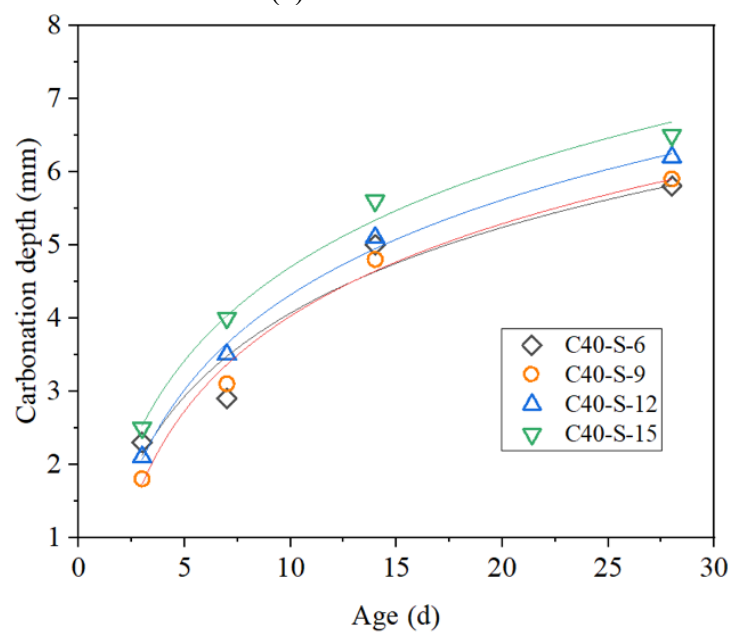

(b) $\mathrm{C} 40$ concrete

Fig. 3 Test results of carbonation depth of waste calcareous rock powder concrete 


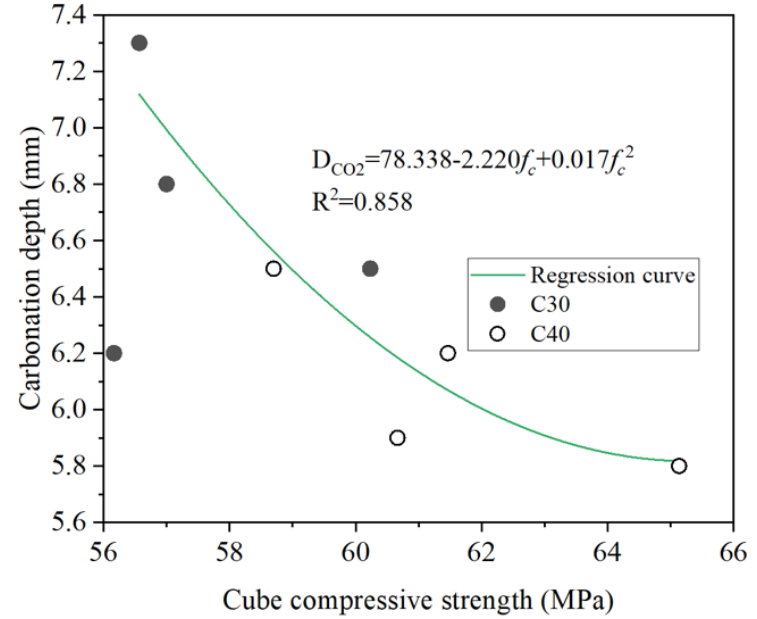

Fig. 4 Correlation between compressive strength and carbonation depth of waste calcareous rock powder concrete

\section{Conclusion}

In this paper, the waste calcareous rock powder formed in the production process of manufactured sand was mixed into the concrete of manufactured sand at $6 \%, 9 \%, 12 \%$ and $15 \%$ respectively to prepare green environmentfriendly concrete. The influence of the rock powder on the concrete performance was analyzed by testing the cube compressive strength and transmission performance (including rapid chloride diffusion coefficient and carbonation depth). The conclusions were as follows:

(1) With the increase of stone powder content, the compressive strength of $\mathrm{C} 30$ concrete first increased and then decreased, while that of $\mathrm{C} 40$ concrete continued to decrease.

(2) The results show that the rapid chloride diffusion coefficient and carbonation depth increased with the increase of stone powder content, in which $9 \%$ stone powder content was the most favorable to improve the performance of concrete. Prolonging the age and reducing the water binder ratio can improve the transmission performance of concrete and make up for the adverse effect of too high stone powder content.

(3) Logarithmic function and polynomial function were used to analyze the correlation between rapid chloride diffusion coefficient, carbonation depth and compressive strength, respectively.

\section{Acknowledgements}

This research was funded by National Natural Science Foundation of China, grant number 51978408, and National Key R\&D Program of China, grant number 2016YFC0701000.

\section{References}

1. X. Song, H. Dong, Z. Huang, J. Xia, Y. Zhou, and J. Wang, China Railw. 31 (2019).

2. R. Yang, R. Yu, Z. Shui, X. Gao, X. Xiao, D. Fan, Z. Chen, J. Cai, X. Li, and Y. He, J. Clean. Prod. 258, 120673 (2020).

3. M. Davraz, H. Ceylan, İ. B. Topçu, and T. Uygunoğlu, Constr. Build. Mater. 165, 494 (2018).

4. K. L. Jain, G. Sancheti, and L. K. Gupta, Constr. Build. Mater. 252, 119075 (2020).

5. I. Taji, S. Ghorbani, J. de Brito, V. W. Y. Tam, S. Sharifi, A. Davoodi, and M. Tavakkolizadeh, J. Clean. Prod. 210, 837 (2019).

6. H. Ding, J. Zhejiang Univ. Water Resour. Electr. Power 31, 55 (2019).

7. J. Yan, X. Ye, Y. Li, S. Liu, B. Chang, and J. Yu, J. Mater. Sci. Eng. 37, 828 (2019).

8. K. Xie, H. Wang, J. Xiao, and D. Yang, J. Archit. Civ. Eng. 36, 31 (2019).

9. S. Sun, J. Water Resour. Archit. Eng. 17, 160 (2019).

10. Z. Liu, Study on Methods of Accelerated Testing of Marine Concrete Durability Based on Simulating Environment and Service Life Prediction, $\mathrm{PhD}$ Thesis, Southeast University, 2006.

11. X. Chen, G. Yuguang, B. Li, M. Zhou, B. Li, Z. Liu, and J. Zhou, Constr. Build. Mater. 240, 117953 (2020).

12. H. Li, F. Huang, G. Cheng, Y. Xie, Y. Tan, L. Li, and Z. Yi, Constr. Build. Mater. 109, 41 (2016).

13. P. Chindaprasirt, C. Jaturapitakkul, and T. Sinsiri, Constr. Build. Mater. 21, 1534 (2007).

14. A. Taha, W. Alnahhal, and N. Alnuaimi, Compos. Struct. 243, 112277 (2020).

15. D. Niu, L. Su, Y. Luo, D. Huang, and D. Luo, Constr. Build. Mater. 237, 117628 (2020).

16. Y. Guo, X. Hu, and J. Lv, Constr. Build. Mater. 223, 142 (2019).

17. S. Kim, Y. kim, M. Usman, C. Park, and A. Hanif, J. Build. Eng. 33, 101641 (2021). 